\title{
Uma reflexão ética sobre o erro médico e a responsabilidade profissional ${ }^{*}$
}

\section{Ethical reflection about medical errors and professional responsability}

\author{
Henrique Caivano SOARES ${ }^{1}$, Marcos de ALMEIDA²
}

SOARES, H.C.; ALMEIDA, M. de. Uma reflexão ética sobre o erro médico e a responsabilidade profissional. Saúde, Ética \& Justiça, 5/7(1-2):12-6, 2000-2002.

Resumo: O autor analisa a responsabilidade profissional do médico no exercécio da profissão. Chama a atenção, entre outras coisas, para a relevância da autonomia de vontade - correspondente à espontaneidade da ação; para a não transferência da responsabilidade moral - colocando-o como agente único de seus próprios atos. Finalizando, caracteriza de maneira pertinente o chamado "erro médico", concluindo então a sua reflexão.

Unitermos: Erros médicos/tendências. Responsabilidade legal. Ética médica. Ética profissional.

\section{Introdução}

$\mathrm{R}^{\mathrm{s}}$ efletir, de maneira ética, sobre o assim chamado "Erro Médico", implicaria num pensamento conjunto sobre a responsabilidade médica, isto é, sobre as responsabilidades que o profissional da medicina tem de lidar, ao exercer 0 seu ofício e a sua arte.

Tratar, na atualidade, deste tema, antigo e clássico, da Medicina Legal, a Responsabilidade Médica, que é, em última análise, o que nos faz responder, em diversas áreas, pelos atos médicos "errados", importaria no duplo compromisso de fidelidade aos princípios já consagrados e de neles equacionar as situações novas da prática médica de alto risco, em razão do próprio desenvolvimento da medicina como ciência e como tecnologia.

\footnotetext{
*Trabalho realizado na Disciplina de Medicina Legal da Universidade Federal de São Paulo / Escola Paulista de Medicina.

1. Professor adjunto da Disciplina de Medicina Legal e Bioética da UNIFESP.

2. Professor titular da Disciplina de Medicina Legal e Bioética da UNIFESP.

Endereço para correspondência: Marcos de Almeida. EPM/UNIFESP. Rua Botucatu, 720 - Vila Clementino, São Paulo, SP - CEP: 01532-000
} 
SOARES, H.C.; ALMEIDA, M. de. Uma reflexão ética sobre o erro médico e a responsabilidade profissional.

\section{Afinal, o que é RESPONSABILIDADE?}

Seu significado literal é: qualidade de ser responsável; obrigação de responder por atos próprios ou de outros; encargo; dívida'.

Do ponto de vista jurídico, é o estado daquele que, tendo aptidão para realizar com pleno discernimento um ato e tendo sofrido legitimamente a imputação deste ato, presta conta das conseqüências de sua ação ou omissão².

O primeiro fato que podemos questionar, diz respeito à possibilidade, ou não, de conceituar-se a responsabilidade do médico, nos dias atuais, pelo mesmo modo pelo qual se encontra ela definida em Hipócrates de Cós $^{3}$. Em outros termos, a pergunta consiste em saber se poderá ser mantido o código de Hipócrates, de há 2.400 anos, para uma ciência, que somente nos últimos 100 anos realizou os seus maiores progressos, tanto que, este último centenário médico é chamado por Jurgen Thorwald ${ }^{4}$ de "O Século dos Cirurgiões".

A idéia central na qual queremos insistir é a de que, atualmente, o médico intervém de maneira mais profunda, ao contrário do passado, onde sua assistência era limitada a recursos rudimentares que não envolviam grandes riscos.

Os recursos a que o médico está, moralmente, obrigado perante a ciência médica - a ponto de, não os utilizando, ser incriminado de omissão - impõemIhe riscos mais graves e mais freqüentes de acidentes. E, diga-se desde já, acidentes em Medicina muitas vezes são rotulados ou chamados de "erros médicos".

O objetivo deste trabalho, é realizar uma reflexão, à luz da ética hodierna, sobre o assim chamado "erro médico", e sobre as responsabilidades, às quais o profissional está sujeito a prestar contas, para si e para a sociedade.

\section{Material e método/Resultados}

Por se tratar de uma análise teórica, estes capítulos não são necessários para o desenvolvimento da idéia, da reflexão e das conclusões obtidas. No entanto, serão acrescentados exemplos processuais legais em cirurgia plástica. Nestes processos, por ser material legal, não poderá haver nenhuma mudança em seu texto, nem mesmo a correção de eventuais erros de português.

\section{Discussão}

Riscos maiores, implicam em assumir responsabilidades maiores, e estas serão cobradas pelo paciente ou pela sociedade, quando da eventual caracterização de um "erro médico".

É evidente que, sem os recursos próprios dos novos avanços da ciência médica, era maior, em princípio, a responsabilidade do médico convocado para lutar contra a enfermidade e a morte. Mas, essa responsabilidade, de natureza sobretudo ética, não Ihe era juridicamente imputável. Ao contrário, restringindo-se a responsabilidade aos meios então possíveis, não havia como nela encontrar-se imprudência, negligência ou imperícia, além dos limites em que esses mesmos meios permitissem conhecer os riscos.

Os impressionantes recursos de que dispõe, agora, a medicina, vieram, porém, a estender aqueles limites, tornando possível o conhecimento dos riscos não imaginados no passado.

$E$, consequentemente, em razão desse maior e melhor conhecimento, haveria de estender-se também a responsabilidade médica sempre que os novos recursos possíveis não tenham sido utilizados, ou tenham sido sub-utilizados ou até mal utilizados.

Assim, embora constituindo em princípio, maior segurança para que a medicina possa conquistar áreas que lhes eram antes desconhecidas e melhor praticar nas áreas já de seu domínio anterior, é evidente que os novos avanços da ciência médica implicam também maiores riscos e maior número de acidentes possíveis, com maior extensão da 
SOARES, H.C.; ALMEIDA, M. de. Uma reflexão ética sobre o erro médico e a responsabilidade profissional.

responsabilidade médica. E, não custa repetir, acidentes em medicina, muitas vezes são rotulados como erros. Contra estes danos, e não contra os médicos, é que o direito tutela o interesse social. Deles é que nasce a responsabilidade civil ou penal e, na existência do erro é que está o critério da responsabilidade. O que primeiramente compete ao Direito é, portanto, a investigação da "culpa".

Sabemos, ao contrário, que para a investigação da culpa e atribuição dos erros médicos, servem os juizes de peritos médicos, como igualmente se socorrem da perícia em todas as matérias que dependem de conhecimentos especializados. É atribuição dos peritos e, portanto, ainda dos médicos, responder se houve ou não um erro, e qual a intensidade da culpa que the deu origem.

Poderia ainda ser argumentado, que o juiz não está obrigado a adotar as conclusões do laudo pericial. Este argumento vale só em princípio, pois, na realidade, não é comum decidir o juiz contrariamente ao laudo. Como não é, por igual princípio, vê-lo decidir contrariamente à lei.

A esta questão associam-se outras, como a legitimidade de aplicação ou não das normas do direito comum, e dos princípios gerais do direito, para julgamento das situações que denominamos de "situações médicas".

Trata-se de um princípio que nos parece oportuno questionar, desde logo antecipando o convencimento do descompasso entre as normas próprias do direito comum, e a impropriedade de sua aplicação para a peculiaridade de que se revestem as situações médicas da atualidade. Estas, relativamente recentes, codificadas em 1988 pelo Código de Ética Médica $^{8}$, aquelas, anciãs, de 1914 até a 1941, através dos Códigos Civil ${ }^{9}$ e Penal ${ }^{10}$, respectivamente.

É importante, ao menos, denunciar o descompasso, que geram situações, muitas vezes chamadas de erros, que são responsabilizados e imputados ao médico, fazendo recair sobre a classe médica um fardo que muitas vezes não merecemos. Ocupa-nos, cada vez mais, compassar o descompasso, pensar e agir eticamente, visando uma profilaxia do erro médico por um lado e, por outro, de sua responsabilização quando verdadeiramente ocorre, fato que traria benefício à todos os envolvidos: pacientes, médicos e juizes.

Quando se fala em responsabilidade e, por conseqüência, na possibilidade de responsabilização do médico por atos praticados (ou não), precisamos ter bem claro no horizonte quais os nossos objetivos quando praticamos um ato médico.

Existiria, afinal, uma obrigação de meios ou de fins para com o seu paciente? Em outras palavras, o médico compromete-se a: bem tratar, bem cuidar, bem operar... ou compromete-se com os resultados, com a melhora, cura ou até com a expectativa do paciente?

Evidentemente, parecem-nos ser, a ciência e a arte médica, compromissadas com os meios, somente com os meios e nunca com os fins. Isto é, o médico se compromete a bem cuidar, a bem tratar, a bem operar, a manter-se atualizado cientificamente ... mas não se compromete com os resultados!

Este não compromisso com os resultados, fica bastante claro uma vez que os resultados não dependem só do médico, mas do próprio paciente e suas peculiaridades anátomo-funcionais e psíquicas, da sua adesão ao tratamento, da sua observância ao que foi prescrito, das condições sócioeconômicas do paciente e até do meio em que ele vive.

Mesmo na especialidade denominada Cirurgia Plástica Estética ou "Cosmética", onde alguns defendem uma espécie de coexistência dos compromissos de meios e resultados, uma vez que os fins de embelezamento ou correção de um discutível defeito anatômico pareçam falar mais alto que os meios para conseguí-los, entendemos que deva imperar o compromisso de meios!

Portanto, responsabilidade e responsabilização do ato médico, deveriam ater-se aos meios, sempre aos meios e somente aos meios, e isto não é pouco! Suscita uma série de reflexões, para não dizer uma série de dúvidas. 
Toda prática médica é lícita, como de resto qualquer prática profissional, desde que satisfeitos os requisitos das habilitações profissional e legal. $O$ que não é lícito, é exercer a prática profissional e, no caso, a prática médica, com imprudência, imperícia, ou negligência. Este é o ato ilícito que a lei pune, obrigando a reparar o dano que dela possa decorrer, através de indenização pecuniária devida ao paciente. Este, em essência, o próprio erro médico, que alguns entendem poder chamar-se de culpa médica.

Nestas modalidades - imprudência, imperícia ou negligência - é que se configura a culpa em geral, e, particularmente, a culpa do médico.

Não praticará erro o médico que nada fizer. Mas não é esse o propósito maior da medicina, entendida como prática comprometida com a ação. Originada, como ciência, arte e profissão, da existência anterior do próprio médico, e entendido o médico como aquele que assumiu o encargo de cuidar (do latim, medeor), o preceito tradicionalmente repetido do "primum non nocere", não poderia sobrepor-se ao princípio ético maior que é o princípio de servir.

Tantas vezes seria mais cômodo para o médico primum non agere; entretanto é o seu dever maior de intervir que o leva a assumir riscos nem sempre possíveis de serem calculados com a segurança que se quer no preceito do non nocere. Estas situações, que se tornam mais comuns para a medicina contemporânea, na qual aos maiores recursos correspondem maiores riscos, obriga-nos a ver naquele preceito mera cautela para a ação do médico, que não deve ultrapassar os limites da prudência, mas que ao mesmo tempo não pode e não deve recear o imperativo ético da intervenção ativa.
No exercício deste compromisso encontrará o médico limitações e riscos. Limitações que, para ele, impõem suspender a ação; riscos que o obrigam a avançar para o desconhecido. Os critérios de julgamento nem sempre serão claros, e o sucesso de sua intervenção ou omissão serão sempre discutíveis. Do ponto de vista ético, porém, valerá o seu convencimento próprio. Se assumiu risco com o propósito de maior proveito para o doente, cumpriu ele o seu dever de médico.

"Apostar na cura envolve riscos; insistir na aposta será assumir riscos"

Resumindo o que foi dito nesta discussão e indo de encontro ao objetivo deste estudo, como tentar caracterizar, numa visão ética, o Erro Médico?

Haveria a necessidade de um ato médico lícito, isto é, feito dentro da lei ou seja, por um médico portador das habilitações profissional (diploma) e legal (inscrição no Conselho Regional de Medicina). Desta ação médica (ativa ou passiva, comissiva ou omissiva), haveria um dano real, demonstrável, passível de ser demonstrado pelo Perito Médico. Ligando o dano sofrido à ação médica executada (ou não), haveria a necessidade da existência da culpa (em quaisquer das suas modalidades aquilianas), ou seja, o médico teria que ter agido (ou não), com negligência, imprudência ou imperícia, jamais com dolo (intenção), mesmo eventual.

Com estes elementos presentes, que não incluem os acidentes (particularmente os imprevisíveis) e muito menos os maus resultados, decorrentes o mais das vezes de condições do próprio paciente, ou de sua expectativa ou esperança no resultado do ato médico ... estaríamos diante de um Erro Médico.

SOARES, H.C.; ALMEIDA, M. de. Ethical reflection about medical errors and professional responsability. Saúde, Ética \& Justiça, 5/7(1-2):12-6, 2000-2002.

Abstracts: The authors discuss the doctor professional responsibility during the practice of profession. Takes in account, between other things, the relevance of the autonomy of will, related tothe expontaneous act and the impossibility of transfering moral responsibility, placing the medical doctor as the only agent of his/her own acts. Finally shows in a proper way the so called "medical malpactice" as a conclusion.

Keywords: Medical errors. Liability, legal. Ethics, medical. 


\section{Referências}

1. Dicionário ilustrado da língua portuguesa da Academia Brasileira de Letras. Rio de Janeiro: Bloch Editores, 1976.

2. Almeida Jr, A.; Costa, J.B. de O. Lições de medicina legal. 13.ed. São Paulo: Ed. Nacional, 1976.

3. Dorland's ilustrated medical dictionary. 28.ed. Philadelphia: W. B. Saunders, 1994.

4. Thorwald, J. O século dos cirurgiões. São Paulo: Hemus Livr. Ed.

5. Derobert, L. Droit médical et deontologie médicale. Paris: Flammarion Médecine-Sciences, 1974.

6. Derobert, L.; Accard, J. Basis legale de la responsabilité medicale. Maroc Med., 55:173-82, 1975.

7. Chiodi, V. Manuale de medicina legale. Palermo: Ed. G. Priulla, 1969.

8. Código de ética médica. Rio de Janeiro: Idéia \& Produções, 1988.
9. Código civil. 40.ed. São Paulo: Saraiva, 1990.

10. Código penal. 2.ed. rev. atual. São Paulo, Ed. Revista dos Tribunais, 1997.

11. Cassel, E. Autonomy and ethics in action. N. Engl. J. Med., 6:333-4, 1977.

12. Dobzhanski, T. The biological basis of human freedom. New York: Columbia University Press, 1956.

13. Schutzer, L.V.L. Ethica deontologia medica e pressuposita. São Paulo, 1981. Tese (Livredocência) - Faculdade de Medicina da Universidade de São Paulo.

14. Pereira, C.M.S. Responsabilidade civil. 9.ed. Rio de Janeiro: Ed. Forense, 2000.

15. Gahret, C.B. The kantian philosophy of space. New York: Oxford University Press, 1939.

16. Eldenstein, L. The professional ethics of the Greek physician. In: Ancient medicine. Baltimore: John Hopkins Press, 1967.

17. Sproviero, J.H. Mala praxis - proteccion juridica del medico. Buenos Aires: Abeledo Perrot, 1994. 